\title{
Socio-demographic and Economic Factors Associated with Adherence to Anti-Tuberculosis Treatment
}

\author{
Hossain $\mathrm{MM}^{1}$, Flora $\mathrm{MS}^{2}$, Shahidullah $\mathrm{M}^{3}$, Amin $\mathrm{MN}^{4}$, Mosharref $\mathrm{M}^{5}$, Wahab $\mathrm{MA}^{6}$
}

DOI: https://doi.org/10.3329/jafmc.v15i1.48639

\begin{abstract}
Introduction: Tuberculosis is one of the most significant health problems in Bangladesh. Adherence to TB treatment is crucial to achieving cure while avoiding the emergenceofdrug resistance. Non-adherence to anti-tuberculosis treatment may result in persistent infectiousness and a higher rate of treatment failure, relapse and drug resistance and therefore, it'sa significant barrier to the success in tuberculosis control.
\end{abstract}

Objectives: To determine the socio-demographic and economic factors influencing adherence to anti-tuberculosis treatment among tuberculosis patients.

Materials and Methods: This case control study was carried out among purposively selected 47 cases and 94 controls in selected DOTS centres of Dhaka city from January 2010 to July 2010. Data were collected by face to face interview using a semi-structured questionnaire.

Results: Males were 2.5 times more likely to be non-adherent and among them day-labourer and main earning member were more commonly non-adherent $(p<0.05)$. Low per capita income and irregularity of monthly income were significantly $(p<0.01)$ associated with non-adherence.

Conclusion: Non-adherence is associated with the risk factors that are modifiable by the correction of socio-demographic and economic characteristics as a whole. So the highest priority in fighting against non-adherence therefore must be to reduce poverty for its prevention especially targeting the patients of low economic status.

Key-words: Tuberculosis, Adherence, Anti- TB treatment.

\section{Introduction}

Tuberculosis (TB) is an ancient disease that has affected mankind for more than 4,000 years ${ }^{1}$. TB remains a leading cause of morbidity andmortality in developing countries, including Bangladesh. In developing countries, about $7 \%$ of all deaths are attributedto TB which is the most common cause ofdeath from a single source of infection among adults. It is the first infectious disease declared by the WHO as a global health emergency². In Bangladesh tuberculosis is a major public health problem. It is estimated that 300,000 new cases crop up each year, of which about half of them are infectious TB. It is further estimated that about 70,000 people die every yearandan incidence of 223/100,000 people per year ${ }^{3}$. TBoccurs more frequently among low-income peopleliving in overcrowded areas and persons with little schooling. Drug resistance, incombination with other factors, results in increased morbidity and mortality due to tuberculosis. The WHO reported alarming rise of notonly multidrug-resistant (MDR) TB but also of extreme drug-resistant TB (XDRTB) globally 4 .

In Bangladesh, the MDR rate is 3.5\% among new cases and $20 \%$ among previously-treated cases 3.5. The death rate in MDR cases is high (50-60\%) andis often associated with a short span of disease (416 weeks $)^{6}$. Several factors have been identified forthe development of MDR. These include non-adherenceto therapy, lack of direct observed treatment, interrupted drug supplies, poorquality of drugs, and widespread availability of anti-TBdrugs without prescription, poor medical management and poorly-managed national control program ${ }^{7}$. In terms of TB control, adherence to treatment may be defined as the extent to which the patient's historyof therapeutic drugtaking coincides with the prescribed treatment ${ }^{8}$. Non-adherence to anti-tuberculosis treatment is a major barrier to the global control of $\mathrm{TB}^{9}$. Poor patient adherence is the most important cause oftreatment failure in tuberculosis programs ${ }^{10}$. Non-adherence may result in persistent infectiousness on the part of the patient and higher rates oftreatment failure, relapse, and drug resistance. Adherence to TB treatment is crucial to achieving cure while avoiding the emergence of drug resistance. Regular and complete medication intake gives individual TB patients the best chance of cure and also protects the community from the spreadof TB. To find out factors influencing the adherence to anti-tuberculosis treatment this study was designed.

\section{Material and Methods}

A case control study was designed and purposively 47 cases were selected from DOTS centers at Middle Badda, Mirpur-1, Hazaribag areas of Dhaka city under $2^{\text {nd }}$ Urban Primary Health Care Project (UPHCP) from January 2010 to July 2010 who were non-adherent TB patients with defaulted or interrupted treatment for two consecutive weeks or more. Un-matched 94 controls who were all new TB patients, received four months or more anti TB therapy and didn't miss more than two consecutive weeks doses were taken as adherent to anti TB treatment. Patients of both sexes between the ages of $16-80$ years were selected for the study and patients with any psychiatric/mental

1. Lt Col Md Motahar Hossain, MBBS, MPH, MPhil, DTM\&H (Thailand), Deputy Contingent Commander, BANMED/5, MINUSCA, Central African Republic (E-mail: motahar856@gmail.com) 2. Professor Meerjady Sabrina Flora, MBBS, MPH, PhD (UK), Director, IEDCR, Mohakhali, Dhaka 3. Brig Gen Md Shahidullah, MBBS, MPH, MPhil, Deputy DGMS, Dhaka 4. Col Md Nurul Amin, MBBS, MPH, Trainee Officer, AFMI, Dhaka 5. Lt Col Murshida Mosharref, MBBS, FCPS, DCH, Classified Specialist in Paediatrics, CMH, Cumilla. 6. Lt Col Md Abdul Wahab, MBBS, MD, Associated Professor of Biochemistry, AFMC, Dhaka. 
disorders, non-pulmonary TB patients, patients having category II treatment were excluded from the study. The sample size were estimated by Epi info software based on the anticipated odds ratio of $3.7 \%$ and case control ratio $1: 2$, at confidence level $95 \%$ with $80 \%$ power of test. Data were collected by using semi-structured questionnaire with face to face interview \& a checklistin their homes, preferably, not in presence of others so that respondents could answer the questions freely. Statistical package for Social Science (SPSS) version 17 for Windows was used to analyze the data.

\section{Results}

A total of 141 participants were enrolled into this case-control study. Among them, 47 non-adherent and 94 adherent anti-TB treatment patients were as case and control respectively. In age distribution of the respondents, cases (83\%) were more than the controls $(74.5 \%)$ in $<45$ years of age, although the age difference between the cases and controls was statistically not significant $(p>0.05)$. Cases $(33.98 \pm 14.93)$ were on average two years younger than the controls $(32.11 \pm 12.31)$. Males participated more than the females and the proportion was higher significantly $(p<0.05)$ in cases $(78.7 \%)$ than controls $(59.6 \%)$. It was observed that, females were 2.5 times $(\mathrm{OR}=0.40,95 \% \mathrm{Cl} 0.18-0.90)$ less likely to develop non adherence than the males. Illiterate and primary education (34.0\% vs $24.5 \%)$ was in higher proportion among cases than controls (34\% vs $23.4 \%$ ). But controls $(41.5 \%)$ were more in higher secondary level than the cases $(29.9 \%)$ which was found insignificant ( $p>0.05)$. Day-laborer was more common in cases $(40.4 \%)$ than the controls $(16.0 \%)$. On the other hand, the controls were predominant in business $(19.1 \%)$, service $(38.3 \%)$ and unemployed $(13.8 \%)$ than the cases. The difference was tested by $\chi 2$ test and found significant $(p=0.014)$. The day-laborers were four times $(O R=4.12,95 \%$ $\mathrm{Cl}=1.11-15.25)$ more likely to become non-adherent than the unemployed. The proportion of residing in kacha house was higherin cases (31.9\%)than the controls $(16.0 \%)$. The $\chi 2$ test revealed that there might be association between types of house and adherence to anti tubercular therapy $(p<0.05)$. Odds ratio showed that those lived in semi-pucca and pucca houses were two times and four times, respectively, less likely to be nonadherent than those lived in kacha house (Table-I).

About $63.8 \%$ of the cases were main earning member and $39.4 \%$ of controls. The difference between two groups were tested by $\chi 2$ test and found highly significant $(p<0.01)$. The odds ratio showed that the main earning members were 2.7 times $(\mathrm{OR}=2.72,95 \% \mathrm{Cl}=1.32-5.61)$ more likely to develop non-adherence than those who were not. Average monthly income Taka $\leq 6000$ were more common among the cases than the controls. The difference in income was found highly significant $(p<0.01)$. Odds ratio showed that, with the increase in family income chance (OR=0.26 95\% $\mathrm{Cl}=0.08-0.80)$ of becoming non-adherent to treatment might decrease. The independent sample t-test showed also highly significant $(p<0.001)$ difference in average monthly income between cases and controls. Higher proportion of cases $(57.4 \%)$ had no regularity in their monthly income than the controls $(27.7 \%)$. But the controls $(72.3 \%)$ were more than the cases $(42.6 \%)$ in regular monthly income of their family. It was also found highly significant $(p=0.001)$.Among the respondents who had regular family income were 3.5 times $(\mathrm{OR}=0.28,95 \% \mathrm{Cl}=0.14-0.59)$ less likely to be non-adherent than with irregular income. In most of the cases (87.2\%) percapita income was $\leq$ US $\$ 1 /$ day than the controls $(70.2 \%)$. Statistically the difference was significant $(p<0.05)$. The odds ratio showed that per capita income $>$ US $\$ 1$ per day were three times (OR=0.35 95\% $\mathrm{Cl}=0.13-0.91$ ) less likely to be non-adherent than those per capita income $\leq$ US\$ 1 per day (Table-II).

Binary logistic regression model was constructed taking nonadherence as dependent variables and all the variables which showed significant association during univariate analysis as independent.This model revealed that, regularity of income $(p<0.05)$ and poverty $(p<0.05)$ remained significant risk factors, whereas sex, occupation, main earning member lostsignificance in this combined model. The model was significant $(\chi 2=34.88$, $p<0.001)$ andcouldcorrectly classify $91.5 \%$ controls, $51.1 \%$ cases and overall prediction was 78\% (Table-III).

Table-I: Socio-demographic characteristics of respondents

\begin{tabular}{|c|c|c|c|c|c|c|}
\hline \multirow{2}{*}{\multicolumn{2}{|c|}{ Characteristics }} & \multicolumn{2}{|c|}{ Case $(n=47)$} & \multicolumn{2}{|c|}{ Control( $n=94)$} & \multirow{2}{*}{ Statistics } \\
\hline & & Number & $\%$ & Number & $\%$ & \\
\hline \multirow{4}{*}{ Age in years } & $16-30$ & 29 & 61.7 & 52 & 55.3 & \multirow{3}{*}{$\begin{array}{c}x 2=1.294 \\
d f=2 \\
p>0.05\end{array}$} \\
\hline & $31-45$ & 10 & 21.3 & 18 & 19.2 & \\
\hline & $>45$ & 8 & 17.0 & 24 & 25.5 & \\
\hline & \multicolumn{6}{|c|}{ Mean $\pm S D$ 32.11 $\pm 12.30833 .98 \pm 14.927 t=0.743$} \\
\hline \multirow{2}{*}{ Sex } & Male & 37 & 78.7 & 56 & 59.6 & \multirow{2}{*}{$\begin{array}{c}\chi 2=5.117 \\
d f=1 \\
p<0.05\end{array}$} \\
\hline & Female & 10 & 21.3 & 38 & 40.4 & \\
\hline \multirow{4}{*}{ Level of education } & |lliterate & 16 & 34.0 & 23 & 24.5 & \multirow{4}{*}{$\begin{array}{c}\chi^{2}=6.405 \\
d f=3 \\
p>0.05\end{array}$} \\
\hline & Primary & 16 & 34.0 & 22 & 23.4 & \\
\hline & Secondary & 14 & 29.9 & 39 & 41.5 & \\
\hline & $\geq$ Higher secondary & 1 & 2.1 & 10 & 10.6 & \\
\hline \multirow{4}{*}{ Occupation } & Unemployed & 4 & 8.5 & 13 & 13.8 & \multirow{4}{*}{$\begin{array}{c}\chi^{2}=12.48 \\
d f=3 \\
p<0.05\end{array}$} \\
\hline & Service & 17 & 36.2 & 36 & 38.3 & \\
\hline & Business & 3 & 6.4 & 18 & 19.1 & \\
\hline & Day-labourer & 19 & 40.4 & 15 & 16.0 & \\
\hline \multirow{3}{*}{ Type of house } & Kacha & 15 & 31.9 & 15 & 16.0 & \multirow{3}{*}{$\begin{array}{c}\chi^{2}=6.819 \\
d f=2 \\
p<0.05\end{array}$} \\
\hline & Semi-pucca & 26 & 55.3 & 53 & 56.3 & \\
\hline & Pucca & 6 & 12.8 & 26 & 27.7 & \\
\hline
\end{tabular}

Table-II: Distribution of the respondents by economic characteristics

\begin{tabular}{|c|c|c|c|c|c|c|}
\hline \multirow{2}{*}{\multicolumn{2}{|c|}{ Characteristics }} & \multicolumn{2}{|c|}{ Case $(n=47)$} & \multicolumn{2}{|c|}{ Control(n=94) } & \multirow[t]{2}{*}{ Statistics } \\
\hline & & Number & $\%$ & Number & $\%$ & \\
\hline \multirow{2}{*}{ Main earning member } & No & 17 & 36.2 & 57 & 60.6 & \multirow{2}{*}{$\begin{array}{c}\chi^{2}=7.522 \\
d f=1 \\
p<0.01\end{array}$} \\
\hline & Yes & 30 & 63.8 & 37 & 39.4 & \\
\hline \multirow{5}{*}{$\begin{array}{l}\text { Average monthly } \\
\text { income in Taka }\end{array}$} & $\leq 3000$ & 15 & 31.9 & 16 & 17.0 & \multirow{4}{*}{$\begin{array}{c}\chi 2=12.664 \\
d f=3 \\
p<0.01\end{array}$} \\
\hline & $3001-6000$ & 22 & 46.8 & 29 & 30.9 & \\
\hline & $6001-9000$ & 6 & 12.8 & 25 & 26.6 & \\
\hline & $>9000$ & 4 & 8.5 & 24 & 25.5 & \\
\hline & \multicolumn{6}{|c|}{ Mean \pm SD $4940.4 \pm 2399.27686 .2 \pm 5211.1 \mathrm{t}=-4.281$} \\
\hline \multirow{2}{*}{$\begin{array}{l}\text { Regularity of monthly } \\
\text { income }\end{array}$} & Not regular & 27 & 57.4 & 26 & 27.7 & \multirow{2}{*}{$\begin{array}{c}\chi 2=11.851 \\
d f=1 \\
p<0.001\end{array}$} \\
\hline & Regular & 20 & 42.6 & 68 & 72.3 & \\
\hline \multirow{2}{*}{ Poverty status } & $\leq$ US $\$ 1 /$ day & 41 & 87.2 & 66 & 70.2 & \multirow{2}{*}{$\begin{array}{c}\chi 2=4.96 \\
d f=1 \\
p<0.05\end{array}$} \\
\hline & $>$ US $\$ 1 /$ day & 6 & 12.8 & 28 & 29.8 & \\
\hline
\end{tabular}


Table-Ill: Logistic regression model for identification of best predictors of non-adherence to anti TB therapy

\begin{tabular}{|l|c|c|c|c|c|}
\hline Characteristics & \multirow{2}{*}{ 2 Wald } & Significance & OR (ExpB) & \multicolumn{2}{|c|}{$95 \%$ Cl for EXP(B) } \\
\cline { 5 - 7 } & & & & Lower & Upper \\
\hline Regularity of income & - & - & 1 & - & - \\
\hline Not regular** & - & 0.022 & 0.353 & 0.145 & 0.863 \\
\hline Regular & 5.219 & - & 1 & - & - \\
\hline Poverty status & - & - & 0.255 & 0.077 & 0.847 \\
\hline SUS\$1/day
\end{tabular}

${ }^{* *}=$ Reference group, $\mathrm{OR}=$ Odds Ratio, $\mathrm{Cl}=$ Confidence Interval, $\operatorname{EXP}(B)=$ Exponential $B$

\section{Discussion}

In this study, male was higher in proportion non-adherent (78.7\%) than adherent $(59.6 \%)$. It was observed that, males were 2.5 times $(\mathrm{OR}=2.51)$ more likely to develop non adherence than the female, more commonly< 45 years of age were non-adherent. The possible reason might be male had the poor attitude to anti TB therapy than female. This finding has got similarity with the finding of a study in Thailand ${ }^{11}$ found female patients were more likely to have excellent compliance than male patients (74.5\%VS $62.0 \%)$ and statistically significant. Female patients were 1.87 times more likely to have excellent compliance than male patients (Adjusted OR = 1.87, 95\% Cl: 1.17-2.99, $\mathrm{p}=.009$ ).

Concerning the education, non-adherence was in higher proportion illiterate than adherence group ( $34 \%$ vs $24.5 \%$ ). This finding consistent with another study in India ${ }^{12}$ found that literacy rate was significantly lower among patients in defaulted in comparison with completed group $(p=0.01)$. In this study most of the respondents lived in urban areas and those lived in semi-pucca and pucca houses were 2.0 times and 4.31 times respectively less likely to be nonadherent than those lived in kacha house. This study also found that widows were more non-adherent which was consistent with the statement of a Chinese study ${ }^{13}$ carried out in Jiangsu province that, Univariateanalysis showed that patients, who were illiterate, divorced/widowed were more likely to be non-adherent. The crude ORs $(95 \% \mathrm{Cls})$ were $2.38(1.37-4.13), 2.42(1.30-4.52)$ respectively.

The present study revealed that, non-adherence to anti-tuberculosis drug was more common among the day-laborers who were 4.1 times more likely to become non-adherent than the unemployed. Percapita income was $\leq$ US $\$ 1 /$ day in most of the non-adherent group $(87.2 \%)$ than the adherents and adherents were three times less likely to become non-adherent than those per capita income >US $\$ 1$ per day. Higher proportion of non-adherent had no regularity in their monthly family income and among the respondents who had regular family income were 3.57 times $(\mathrm{OR}=0.28,95 \% \mathrm{Cl}=0.14-0.59)$ less likely to be non-adherent than with irregular income. The main earning members were 2.72 times $(\mathrm{OR}=2.72)$ more likely to develop nonadherence than those who were not the main earning member. The possible reasons might be job as well as economic insecurity. Similar findings were found in several studies in Nepa ${ }^{14}$ and Thailand ${ }^{11}$.

\section{Conclusion}

This study found that there were significant differences between adherent and non-adherent groups in terms of socio-demographic and economic factors as poverty and regularity of income were more likely to be the risk factors for adherence to antiTB treatment. The cause of non-adherence to treatment in this population appears to be multi-factorial. Socio- demographic and economic factors for adherence to anti-TB treatment are more or less similar in the developing countries. These risk factors for nonadherence are modifiable by the correction of socio-demographic and economic characteristics as a whole. So, the highest priority must be to reduce poverty in fighting against non-adherence for its prevention.

\section{References}

1. Brief history of tuberculosis. (http://www.umdnj.edu/ ntbcweb/history. htm, accessed on 1 March 2010).

2. Kochi A. The global tuberculosis situation and the new control strategy of the World Health Organization. Tubercle 1991; 71:1-6.

3. World Health Organization. Global tuberculosis control 2008: epidemiology, strategy, financing: WHO report 2008. Geneva: World Health Organization, 2008:303. (WHO/HTM/TB/2009.411).

4. Cantwell MF, Mckenna MT, McCray E et al. Tuberculosis and race/ ethnicity in United States: impact of socioeconomic status. Am J Respir Crit Care Med 1998; 157:1016-20.

5. Shetty N, Shemko M, Abbas A. Knowledge, attitudes and practices regarding tuberculosis among immigrants of Somalian ethnic origin in London: Across sectional study. Commun Dis Public Health 2004; 7:77-82.

6. Rattan A, Kalia A, Ahmad N. Multidrug- resistant Mycobacterium tuberculosis: molecular perspectives. Emerg Infect Dis 1998; 4:195-209.

7. Zaman K, Rahim Z, Yunus M et al. Drug resistance of Mycobacterium tuberculosis in selected urban and rural areas in Bangladesh. Scand J Infect Dis 2005; 37:21-6.

8. Urquhart J. Patient non-compliance with drug regimens: Measurement, clinical correlates, economic impact. European Heart Journal, 1996; 17(Suppl A):8-15.

9. Vermeire $E$, Hearnshaw $H$, van Royen $P$ et al. Patient adherence totreatment: three decades of research. A comprehensive review. J Clin Pharmacol Ther 2001; 26:331-42.

10. Dixon-Woods M, Shaw RL, Sagarwal A et al. The problem of appraising qualitative research. Qual Saf Health Care 2004; 13:223-5.

11. Lertmaharit $S$, Kamol PR, Sawert $H$ et al. Factors Associated with Compliance among Tuberculosis Patients in Thailand J Med Assoc Thai 2005; 88(Suppl 4): S149-56.

12. Frederick ADK, Mary $T$, Seter $S$ et al. An assessment of factors contributing to treatment adherence and knowledge of TB transmission among patients on TB treatment BMC Public Health 2004, 4:68.

13. XuW, LuW, ZhouY et al. Adherence to anti-tuberculosis treatment among pulmonary tuberculosis patients: a qualitative and quantitative study; BMC Health Services Research 2009, 9:169.

14. Mishra P, Hansen EH, Sabroe $S$ et al. Socio-economic status and adherence to tuberculosis treatment: A case-control study in a district of Nepal; INT J TUBERC LUNG DIS 2005; 9(10):1134-9. 